\title{
LEACHING AND TRANSPORT OF Zn THROUGH SOIL PROFILES IN A SEASONAL RIVER OF A MINING AREA IN SE SPAIN
}

\author{
G GARCIA $^{1^{*}}$ \\ J.I. MANTECA ${ }^{2}$ \\ J.M. PEÑAS ${ }^{1,2}$
}

Received: 22/12/06

Accepted: 02/04/07

\author{
${ }^{1}$ Soil Science and Agriculture Chemistry Unit \\ Agriculture Science and Technology Department \\ Technical University of Cartagen \\ Paseo de Alfonso XIII48, E-30203, Cartagena. Spain \\ ${ }^{2}$ External Geodynamic Unit \\ Mining, Geological and Cartographic Engineering \\ Department, Technical University of Cartagena \\ Paseo e Alfonso XIII, 52, E-30203, Cartagena. Spain
}

*to whom all correspondence should be addressed: e-mail: gregorio.garcia@upct.es

\begin{abstract}
Metal pollution can have adverse effects on human health but also on environment. Usually, risk is assessed on the basis of the total concentration of a trace metal in soils and sediments. Nevertheless, for checking the short and long-term true environmental impact of a trace element, one of the most crucial factors to consider is its mobility. Leachability of metals from soils and sediments and, thus, their mobility, depends on several factors such as the soil type on the basis of the parameters that affect metal interaction, the nature of the pollution in terms of the deposition and composition, and finally the environmental conditions that may lead to weathering. This study has been focused on the metal behaviour in some soil and sediment profiles placed in the river-bed of a seasonal river from a semiarid mining Mediterranean area, in SE Spain. Data from these analyses showed that a change of the environment conditions could remobilise great amounts of $\mathrm{Zn}$. In this sense, a change of acidic conditions could affect mainly to the lower drill. Meanwhile a change of reducing or oxidizing conditions can affect to middle and upper drills zinc remobilization. Middle stretch of the seasonal river shows a very different behaviour in relation to zinc mobility, leachibility and distribution in soil profiles. For this river stretch, metal accumulation in the soil profile is higher, and leachibility risks for groundwater could be higher. Besides, the lower stretch of the seasonal river show a special metal distribution because of the underlying materials are placed in the saturated zone (marine aquifer), what can determinate a horizontal, more than a vertical, metal flux.
\end{abstract}

KEYWORDS: Zinc pollution; leaching; mobility; groundwater; risk.

\section{INTRODUCTION}

SE of the Iberian Peninsula and specially Cartagena-La Union mining District has constituted an important mining nucleus for more than 2500 years. Throughout this period, Phoenicians, Romans, Carthaginians and Spaniards have been mining in this district for silver, lead, zinc, copper, tin, iron, and manganese in an area of about 50 square $\mathrm{km}$. Nevertheless, the extractive activity reached a higher intensity in the 19th century, with a maximum during the second half of the XX century with opencast exploitations. As a consequence of the mining activity and the mineral washing operations, huge quantities of mine wastes enriched in metals were produced and still remains all over the area.

As a consequence, and after the decline and ending of this activity, high amounts of wastes have been generated. These materials, accumulated on the surface, contain important levels of heavy metals, such as lead, copper and zinc, being reported also, cadmium and arsenic. This accumulation of heavy metals in soils is of great ecological significance because of their 
well known effects on the biological activity of soils and on their physic-chemical characteristics and properties. The adverse effects of metal exposure on human health are well known, as well.

As a result, heavy metals contamination in natural soils, waters and sediments is a major problem for human health and quality of environment in many countries. Those sites are environmentally dangerous, especially for agricultural and fisheries of the surrounding areas. The occurrence, origin and mobility of metals in waters, soils and sediments have received significant attention in recent years. Risk is often assessed on the basis of the total concentration of a trace metal in soils and sediments. In a matrix and depending on the soil and sediment structure and chemistry, metal reactions affect the solubility, mobility, chemical form and toxicity of the pollutant, but also the metal leaching. In order to assess the short and long-term true environmental impact of pollutants, one of the most crucial factors to consider is its mobility (Gorder and Dahn, 1981; Poirria et al., 1972; Selim and Zhu, 2002). The transport of potentially harmful substances, such as heavy metals through the soil profile into the groundwater has been a major environmental concern (Emmerich et al., 1982; Davies, 1994). However, any efforts toward describing and predicting contaminant transport cannot succeed if major pathways and mechanisms for transport are not well understood (Seta and Karathanasis, 1997; Thomas and Phillips, 1979; Zhang et al., 2000).

Leachability and erodibility of trace elements from soils and sediments and, thus, their mobility depends on several factors such as the soil type on the basis of the parameters that affect metal interaction (e.g. texture, $\mathrm{pH}$ ), the nature of the pollution in terms of the deposition and composition (e.g. soluble or particulate, continuous input or point source emission), and finally the environmental conditions that may lead to weathering (e.g. temperature, water regime, redox processes).

In order to assess dynamics of the availability and mobility of metals, a better evaluation of metal fractioning provides a more useful estimation of real risks, since this speciation studies are related to specific bioavailability, reactivity and metal mobility (McBride, 1994; Luo and Christie, 1998). The mechanisms concerning metal accumulation in soil lead to the existence of five major geochemical forms (Tessier et al., 1979), that have remarkable differences in mobility, biological availability and chemical behaviours in soils and sediments.

There is a requirement for further studies that can provide information on the mobility and dynamics of metals in polluted natural areas. The studied seasonal river, or rambla, called rambla de El Beal, rise in the heart of the mining mountains and runs for $7 \mathrm{~km}$ up to reach the Mar Menor coastal lagoon (Murcia province, SE Spain). Erosive processes have dispersed sediments enriched in heavy metals, and the rambla have acted as a transport way for these polluted sediments from upper to lower areas. Therefore, the soils and sediments of the rambla and surroundings contain high heavy metal concentrations. Because of metal mobility and leaching, the pollution by heavy metals is not only superficial. Thus, trace elements are able to move through the profile up to deeper lawyers.

The objectives of this study were (a) to identify the physicochemical properties of soils which affect mobility and metal transport into deep layers and groundwater; and (b) to assess the metal distribution in soil profiles and leaching from representative soil samples with diverse mineralogy and soil properties. In this sense, this study has been focused on the zinc behaviour in some soil and sediment profiles placed in the river-bed of a seasonal river from a semiarid mining Mediterranean area. This metal has a high mobility under acidic conditions (Kabata-Pendias \& Pendias, 1992), what can increase the risk of erosion and leaching for Zn.

\section{MATERIALS AND METHODS}

The study area (110 - 0 m a.s.l.; $37^{\circ} 37^{\prime} 20^{\prime \prime} \mathrm{N}, 0^{\circ} 50^{\prime} 55^{\prime \prime} \mathrm{W}-37^{\circ} 40^{\prime} 03^{\prime \prime} \mathrm{N}, 0^{\circ} 48^{\prime} 12^{\prime \prime} \mathrm{W}$ ) has been placed in the Cartagena-La Unión Mining District, SE Spain (Fig. 1). This area has a typical termomediterranean climate with a temperature that average of $18{ }^{\circ} \mathrm{C}$ through out the year and a precipitation per year that ranges from $200 \mathrm{~mm}$ to $300 \mathrm{~mm}$.

For the realization of this study three core drills in different points up to downstream in a typical Mediterranean polluted 'rambla' riverbed, strongly affected by metal contamination were achieved. One drill in the source of high part of the riverbed (A), other one in the middle 
point of the rambla (B) and the last one (C) in the point which the rambla flowed into the lagoon (low part). Therefore, drill $C$ is the closest to the coast and $A$ the most far away. The depths of the drills were of 3,6 and $6 \mathrm{~m}$ respectively. In drill $\mathrm{C}$ the seawater level was found at a depth of $1.50 \mathrm{~m}$, while water level was not reached for the other drills.

The samples used in the study were taken at intervals of $25 \mathrm{~cm}$ for the first meter, and of 1 meter for the remaining depths. From these samples one aliquot of $30 \mathrm{gr}$ was taken for analysis. Soil samples were air-dried and crushed to pass through a $2 \mathrm{~mm}$ sieve, homogenized and stored in plastic bags. The dried sediments were ground to a fine powder using an agate mortar, and stored in polypropylene bottles at room temperature till analysis.

The procedure followed for the determination of $\mathrm{pH}$ and electrical conductivity (E.C., dS m-1) is an adaptation of that described in the Official Spanish Analysis Methods for Soils (Metodos Oficiales de Analisis, 1994; Tomo III, pp. 223-225 and 239-240). It should be highlighted the fact that usual methods of measuring soil $\mathrm{pH}$ seriously underestimate the $\mathrm{pH}$ of very acid soils, such as those of mining areas enriched in sulphates and sulphides. Standard methods for measuring soil $\mathrm{pH}$ involve making slurry of soil with (usually) distilled water with the erroneous assumption that the soil is buffered and hence that $\mathrm{pH}$ does not change with dilution. Therefore, in this case ten millilitre of double deionised water were added to $10 \mathrm{~g}$ of the sediment. The mixture was stirred for $10 \mathrm{~min}$ and allowed to settle for $30 \mathrm{~min}, \mathrm{pH}$ and conductivity measurements were performed in the supernatant (Doemel and Brock, 1971). Although this paper is focused on $\mathrm{Zn}$, other metals such as $\mathrm{Pb}, \mathrm{Cd}, \mathrm{Cu}, \mathrm{Sn}, \mathrm{As}, \mathrm{Mn}, \mathrm{Al}, \mathrm{Cr}, \mathrm{Co}$ and $\mathrm{Ni}$ are also present in this mining area.

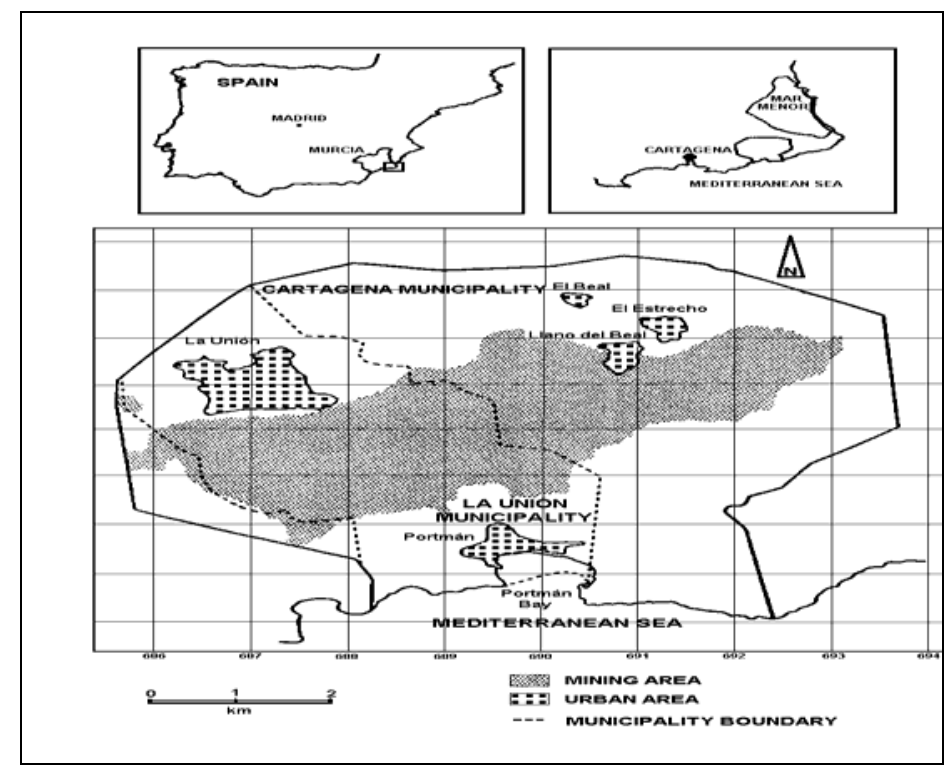

Figure 1. Location of the study area

Soil particle density $\left(\mathrm{g} \mathrm{cm}^{-3}\right)$ is mass of soil solids (oven-dry) per unit volume of soil solids. Particle density depends on the densities of the various constituent solids and their relative abundance. For the evaluation of the particle density, the procedure was based on the picnometer method. It is easy to measure the mass of a small sample of soil but not so easy to accurately measure the volume of soil solids that make up this mass. Briefly, the volume of a known mass of soil solids is determined by indirectly measuring the volume of water displaced by the soil solids. The mass of water displaced is actually measured, then the corresponding volume found from the known density of water.

For soluble metals, this soil-water mixture was stirred up to $2 \mathrm{~h}$. the solutions were filtered using an ash-free filter paper (Albet $n^{\circ} 145$ ) and their volume was made up to $20 \mathrm{ml}$ by the addition of $\mathrm{HNO}_{3} 0.5 \mathrm{~mol}^{-1}$. These solutions were stored at $4{ }^{\circ} \mathrm{C}$ in polypropylene bottles until analysis. 
Otherwise, a modified three-step, but more exactly four steps because of the last step for residual fraction, was made for studying metal mobility. This procedure was an improved version of the initial BCR three-step (Sahuquillo et al., 1999):

- First step: $40 \mathrm{ml}$ of acetic acid $0.11 \mathrm{~mol} \mathrm{I}^{-1}$ were added to $1 \mathrm{~g}$ of sediment in an 80-ml PTFE centrifuge tube. The tube was then shaken in an 'end-over-end' shaker for $16 \mathrm{~h}$ (overnight) at room temperature. The extract was separated from the solid residue by centrifugation at $3000 \mathrm{~g}$ for $20 \mathrm{~min}$ and the supernatant liquid was decanted into a polyethylene container and stored at $4{ }^{\circ} \mathrm{C}$ until analysis.

- Second step: $40 \mathrm{ml}$ of hydroxylamine hydrochloride $0.5 \mathrm{~mol} \mathrm{I}^{-1}(\mathrm{pH}: 1.5$ with the addition of $\mathrm{HNO}_{2}$ mol I${ }^{-1}$, according the procedure) were added to the residue from step 1 in the centrifuge tube, and the extraction was performed as above.

- Third step: $10 \mathrm{ml}$ of hydrogen peroxide $8.8 \mathrm{~mol} \mathrm{I}^{-1}$ was added carefully, in small aliquots to avoid loss due to violent reaction of the residue in the centrifuge tube. The tube was then covered loosely with a stopper and digestion was allowed to proceed for $1 \mathrm{~h}$ at room temperature with occasional manual shaking. The digestion was continued by heating the covered tube for $1 \mathrm{~h}$ at $85^{\circ} \mathrm{C}$ in a water bath, and then the volume was reduced to a few millilitres by further heating of the uncovered tube. A further aliquot of $10 \mathrm{ml}$ of hydrogen peroxide was added to the residue. The tube was covered again and heated at $85^{\circ} \mathrm{C}$ for $1 \mathrm{~h}$. Then the stopper was removed and the volume reduced almost to dryness. After cooling, $50 \mathrm{ml}$ of ammonium acetate $1.0 \mathrm{~mol} \mathrm{I}^{-1}$ were added to the residue and the tube was then shaken in an 'end-over-end' shaker for $16 \mathrm{~h}$ (overnight) at room temperature. The remaining operations for separation of the extract were as above.

- Fourth step: The residue from step 3 was transferred to a suitable digestion vessel and was digested with aqua regia following a modification what follows. A modification of ISO norm 11466 (Soil Quality, 1995) using a microwave digester was adopted as digestion method. As reagents, aqua regia was used in a proportion of $9 \mathrm{ml}$ of $\mathrm{HC}$ $37 \%$ and $3 \mathrm{ml}$ of $\mathrm{HNO}_{3} 65 \%$ per each $0.5 \mathrm{~g}$ of soil sample. The microwave program had two steps, the first during $10 \mathrm{~min}$ for reaching from 0 to $200^{\circ} \mathrm{C}$ at a microwave power of 1000 Watt. The second lasted $15 \mathrm{~min}$ at $200^{\circ} \mathrm{C}$ and the same microwave power than before. For that, a scientific microwave Milestone, Ethos Plus (Microwaves Laboratory Systems) was used. Once cooled down, the solutions were filtered using an ash-free filter paper (Albet $n^{\circ} 145$ ) and their volume was made up to $100 \mathrm{ml}$ by the addition of $\mathrm{HNO}_{3} 0.5 \mathrm{~mol} \mathrm{I}^{-1}$. These solutions were stored at $4{ }^{\circ} \mathrm{C}$ in polypropylene bottles until analysis.

All laboratory glassware and plastic ware were first cleaned with deionised water, then with nitric acid 10\% (for at least $12 \mathrm{~h}$ ) and rinsed again with double deionised water. On the other hand, reagents used in the analysis were of analytical grade quality and the acids used for residual fraction digestions were for trace metal analysis (Scharlab, The Lab Sourcing Group). All solutions and dilutions were performed with double deionised water (18.2 $\vee$ cmy 1 ) obtained from a Milli-Q Academic (Millipore Corporation, MA, USA).

Stock standard solution ( $1 \mathrm{~g} \mathrm{I}^{-1}$ of pure metal higher than $99.99 \%$ from Panreac Quimica S.A.) acidified with nitric acid were used for calibration. Intermediate standards and reagent solutions were stored in glass bottles to avoid possible $\mathrm{Zn}$ contamination from plastic. Preparation of samples, reagents and standards were performed in a clean laboratory. Users carry out a strict maintenance of the laboratory. Final concentrations of $\mathrm{Zn}$ in the solution were determined by flame atomic absorption spectroscopy (UNICAM 969 AA spectrometer) and by inductively coupled plasma atomic mass spectroscopy with an autosampler model (ICP-MS 4500 Agilent Technologies, Wilmington, DE). In all ICP-MS measurements, multielemental solution with $\mathrm{Yb}, \mathrm{In}, \mathrm{Co}, \mathrm{Rh}$ and $\mathrm{Tl}$ at $10 \mathrm{ppb}$ was used as internal standard.

\section{RESULTS AND CONCLUSIONS}

Stratigraphy of the three drills showed a huge influence of mining sediments, mainly in the first meter. It must be taken into account that the studied seasonal river is placed in a typical 
Mediterranean mining area. The first drill was placed in the source, or higher part of the riverbed (A), the second drill was at the middle point of the rambla (B) and the third drill (C) was located in the lower part in point which the rambla flowed into the lagoon.

During November of 2005, these drills were bored by rotation, with continuous core sampling recovery. These cores were used to characterize sediments, with a thickness between 1.80 and $4.30 \mathrm{~m}$ for mining sediments. For drill A, mining sediments were separated in two horizons; the first one ranged from 0.00 to 1.00 and was yellowish oxidised silt. The second one corresponds with dark grey non oxidised silt, and ranged from 1.00 up to $1.80 \mathrm{~m}$ depth. From this point downwards up to 3.00 all the cores corresponded to bed rock. This drill was in the upper part of the seasonal river.

Drill B shows yellowish sand and silts from 0.00 to $0.30 \mathrm{~m}$, fine yellowish gravel and rock fragments from 0.30 to $1.20 \mathrm{~m}$, and gravel and coarse brown sands with rock fragments from 1.20 to $2.70 \mathrm{~m}$ depth. These three fractions corresponded to mining wastes and sediments, more or less mixed with natural downpours. From 2.70 up to $3.00 \mathrm{~m}$ there were silty sands and dark gravels, which became dark gravel from 3.00 to 4.20 m. Finally, bed rock appeared from 4.20 to $6.00 \mathrm{~m}$ depth. This drill was placed in the middle point of the seasonal river run.

Finally, drill $C$ had yellowish mining silts from 0.00 to $0.85 \mathrm{~m}$ depth. From 0.85 to $3.40 \mathrm{~m}$ the sediments corresponded to grey sands with shells, which became dark grey silty sands from 3.40 to $4.00 \mathrm{~m}$. In the range 4.00 to 4.30 appeared black sapropelic silts coming from a reducing environment of the nearby lagoon. Finally, from 4.30 to $6.00 \mathrm{~m}$ all the materials corresponded to bed rock. Seawater level was found at a depth of 1.50-2.0 m.

Soil $\mathrm{pH}$, electrical conductivity and particle density of the studied soils were listed in Table 1. The surface soils of the three drills could be considered as Spolic Anthropic Regosols enriched in sulfates and iron oxides according to the international nomenclature of soils (FAOISRIC-ISSS, 1998). Regarding $\mathrm{pH}$, only surface layers of drill C showed a strong acid reaction at $\mathrm{pH} 4.45$ and 5.39, which mean that metals there will have a higher mobility. The soil pH of drill $A$ and $B$, and the rest of layers of drill $C$ showed a $\mathrm{pH}$ almost neutral with higher values over 7.5, probably due to the presence of the free $\mathrm{CaCO}_{3}$ in the soil.

The particle density of most mineral soils lies between 2.5 and $2.7 \mathrm{~g} \mathrm{~cm}^{-3}$ (Brady, 2002). The range is fairly narrow because common soil minerals differ little in density. An average value of $2.65 \mathrm{~g} \mathrm{~cm}^{-3}$ is often assumed. In contrast, organic soils have lower particle densities since the density of organic matter is much less than that of mineral particles. For the studied soils, density agree with these generic density values for mineral soils; nevertheless, for surface layers these values were even higher (Table 1) what could be related with their mineralogy and the enrichness in heavy metals coming from the mining wastes that constitute these soil layers.

The behaviour of zinc in function of depth has been studied for every drill. This metal was chosen because of its representativeness of the different river stretches.

For drills $A$ and $C$, the highest zinc concentration can be found in the first meter from the soil surface (Figure 2 and 4 ), what agree with the higher particle density of these layers. Any case, for drill B, zinc concentration increases with depth, with a major accumulation between the second and fourth meter (Figure 3). Soluble fractions are low for most of the samples, when compared with the total metals found in the other extractions, what is according to high $\mathrm{pH}$ values. After a comparation between $\mathrm{Zn}$ concentrations in the three drills, it can be checked that drill $B$, which is placed in the middle stretch of the seasonal river, shows the highest $\mathrm{Zn}$ concentration values, with some concentrations that reach more than $40.000 \mathrm{ppm}$ of this metal. On the other hand, for the other drills there were not values higher than 4000 ppm in both cases. 
Table 1. Soil parameters for the three drills

\begin{tabular}{|c|c|c|c|c|c|c|c|c|c|}
\hline \multirow{2}{*}{$\begin{array}{l}\text { Samples } \\
\text { Depth } \\
\text { (cm) }\end{array}$} & \multicolumn{3}{|c|}{ Drill A } & \multicolumn{3}{|c|}{ Drill B } & \multicolumn{3}{|c|}{ Drill C } \\
\hline & $\mathrm{pH}$ & $\begin{array}{l}\text { E.C. } \\
\left(\mathrm{mS} \mathrm{cm}^{-1}\right)\end{array}$ & $\begin{array}{l}\text { Particle } \\
\text { density } \\
\left(\mathrm{T} \mathrm{m}^{-3}\right)\end{array}$ & $\mathrm{pH}$ & $\begin{array}{l}\text { E.C. } \\
\left(\mathrm{mS} \mathrm{cm}^{-1}\right)\end{array}$ & $\begin{array}{l}\text { Particle } \\
\text { density } \\
\left(\mathrm{T} \mathrm{m}^{-3}\right)\end{array}$ & $\mathrm{pH}$ & $\begin{array}{l}\text { E.C. } \\
\left(\mathrm{mS} \mathrm{cm}^{-1}\right)\end{array}$ & $\begin{array}{l}\text { Particle } \\
\text { density } \\
\left(\mathrm{T} \mathrm{m}^{-3}\right)\end{array}$ \\
\hline $0-25$ & 6.79 & 6.04 & 2,88 & 7.71 & 3.36 & 2,83 & 4.45 & 9.61 & 2,71 \\
\hline $25-50$ & 6.77 & 6.04 & 2,56 & 7.49 & 3.15 & 2,71 & 5.39 & 9.16 & 2,86 \\
\hline $50-75$ & 7.18 & 5.33 & 2,69 & 7.48 & 3.25 & 2,72 & 6.6 & 8.14 & 2,59 \\
\hline $75-100$ & 7.25 & 4.61 & 2,71 & 7.46 & 3.12 & 2,93 & 7.25 & 7.64 & 2,52 \\
\hline $100-200$ & 7.3 & 5.95 & 2,70 & 7.22 & 3.13 & 2,58 & 7.29 & 11.18 & 2,58 \\
\hline $200-300$ & 7.57 & 3.16 & 2,68 & 6.86 & 3.09 & 2,86 & 7.62 & 15.96 & 2,59 \\
\hline $300-400$ & - & - & - & 7.43 & 3.18 & 2,52 & 7.8 & 7.11 & 2,94 \\
\hline $400-500$ & - & - & - & 7.31 & 3.28 & 2,77 & 7.53 & 15.75 & 2,60 \\
\hline $500-600$ & - & - & - & 7.52 & 3.15 & 2,20 & 7.28 & 16.03 & 2,55 \\
\hline
\end{tabular}

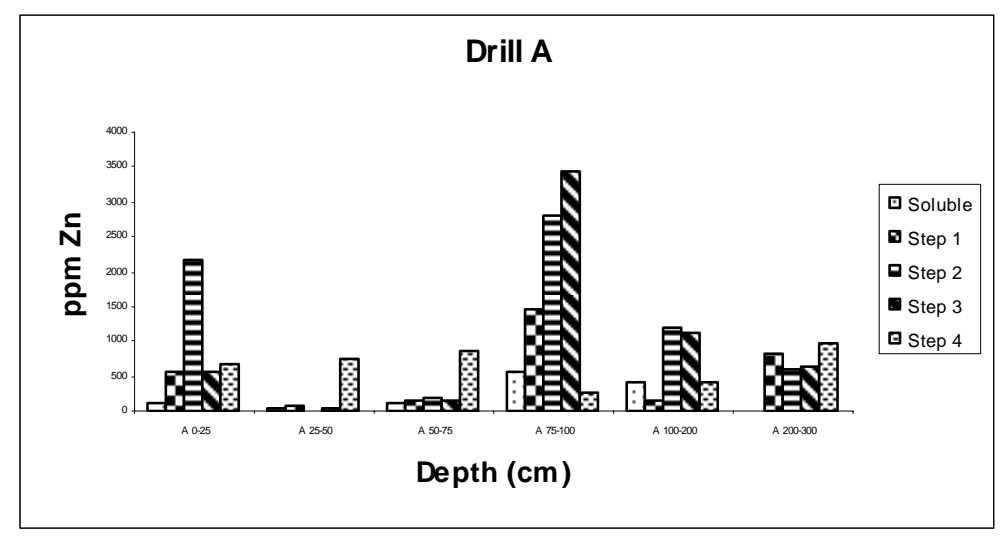

Figure 2. Metal concentration for each depth of drill A

According to these data, it seems that the middle stretch of the rambla shows a very different behaviour in relation to zinc mobility, leachibility and distribution in soil profiles. Therefore, in the high and low stretches of the seasonal river this metal can be mainly found in the upper meter of the profile and with not too high concentrations. In the contrary, in the middle stretch of the river, metal accumulation in the soil profile is quite bigger, with total concentrations up to ten times higher than in the other part of the river, and with higher accumulation in deeper layers, what means that leachibility in this stretch can be bigger. Therefore, leachibility risks and hazards for groundwater should be higher in the middle stretch of this seasonal river. When compare this seasonal river run with the existence of underlying aquifers (RoblesArenas et al., 2006) it can be checked that most of the surface aquifers are placed under the middle and low stretches of the river. Therefore, due to the high leachibility of metals in the middle part of the river run and the presence of surface aquifers in this stretch of the river, it involves a major pollution hazard for groundwaters just in this part of the seasonal river.

The results obtained from the application of the improved version of the initial BCR three-step (Sahuquillo et al., 1999), have been summarised in graphs for zinc in the three drills. The highest extractable amounts of $\mathrm{Zn}$ were found in different steps for each depth and drill. For drills $A$ and $B$ the metal is shared by different fractions (reducing and easily oxidised fractions) (Fig. 2 and 3). On the other hand, drill $C$ shows the higher zinc concentrations in step 1 fraction (acidic conditions), but also in soluble fractions for surface samples with more acid conditions.

Besides, for drill C, Zinc mainly accumulated in soil surface $(0-50 \mathrm{~cm})$ and sharply decreased with increasing soil depth, and the concentration of $\mathrm{Zn}$ in 1-5 $\mathrm{m}$ depth of drill was similar with that of uncontaminated soil, which indicates that $\mathrm{Zn}$ was almost not migrated and has less potential to pollute groundwater. In order to explain this situation, it must be taken into 
account that for this drill, only the first $85 \mathrm{~cm}$ should be considered as soil. From this point downwards all the materials should be considered as marine sediments, with a bioclastic origin and continuously under swell influence. The marine-lagoon sediments of drill C are older that the mining activity and they have not a significant contamination. In others words, we can conclude that the natural weathering of possible outcropping mineral deposits, did not provoke a noteworthy contamination of the lagoon sediments. Therefore, the present soil contamination is the result of mining activity in recent times (XIX and XX centuries). Mar Menor lagoon is a basin that is suffering a regression process. Thus, a great part of the sea sediments are actually covered by continental sediments, mostly with a mining origin.

In case of pollution of these bioclastic sands, it could be explained by leaching from the upper mining sediment layers; nevertheless, this pollution has not yet been detected. This fact could be explained because of the underlying materials are placed in the saturated zone (marine aquifer); therefore, there is not a vertical flux of leaching, but a horizontal flux could be happening. As a consequence of it, it could be considered that in the area around drill $C$, just at the end of the seasonal river in the sea, pollution is mainly following a horizontal direction. On the other hand, in the middle (drill B) and upper (drill A) stretches of the seasonal river, leaching is the mainly factor with influence on pollution, that can more frequently affect to deeper layers. All these data seems to be corroborated by the results of this research (Fig. 2, 3 and 4).

The mobility and migration capacity of Zn was much different for different studied soils, which would be related to adsorption and migration capacity of $\mathrm{Zn}$ in the readily dispersible colloids of different soils (Evangelou and Karathanasis, 1991) and with physicochemical soil conditions (Evangelou and Karathanasis, 1991; Seta and Karathanasis, 1997). This different behaviour must be related with the seawater influence on drill C. Metals and other contaminants transport into soil seem to be associated with the mobile aqueous phase or with the immobile solid phase (Davis, 1982; Guo and Chorover, 2003). Regarding this, some pollutants with a strong tendency to bind to the solid phase and with a low solubility in water are assumed to be almost immobile and, therefore, with little risk to affect to the deep soil layers, or even the groundwater (Sauerbeck, 1991; Van Olphen, 1977). On the contrary, colloids that are easily dispersible in the solid phase may also be mobile in subsurface environments (Guo and Chorover, 2003; Selim and Zhu, 2002). Metal mobility and transport capacity of the readily dispersible colloids entering the deep layers depends on solution chemistry and to a greater extent, on the colloids' physicochemical, mineralogical, and electrokinetic properties (Evangelou and Karathanasis, 1991; Melis et al., 1983; Tessens, 1984; Van Olphen, 1977). Relationships between these properties and mechanisms enhancing the metal mobility have not been established.

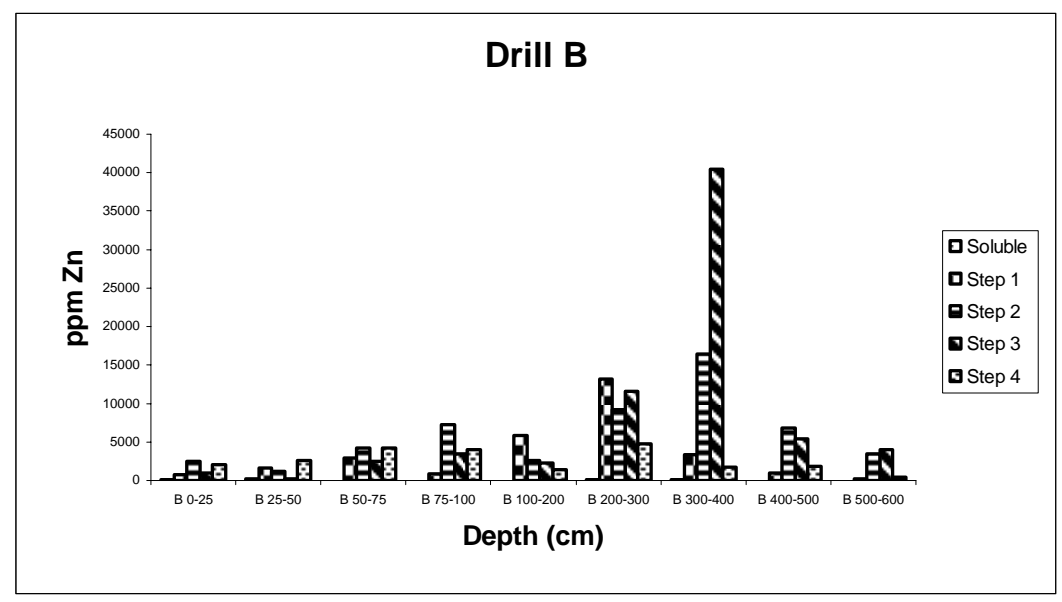

Figure 3. Metal concentration for each depth of drill B

Taking into account the values for heavy metals in the studied soils and sediments from the drills and the Spanish regulations (Real Decreto 1310/1.990), for agricultural soils with $\mathrm{pH}$ 
higher than 7, zinc is over the allowed limits (450 ppm). Something happens in relation with Dutch (Ewers, 1.991) and Turkish regulations (Yukselen, 2002), which limits are of 3000 ppm.

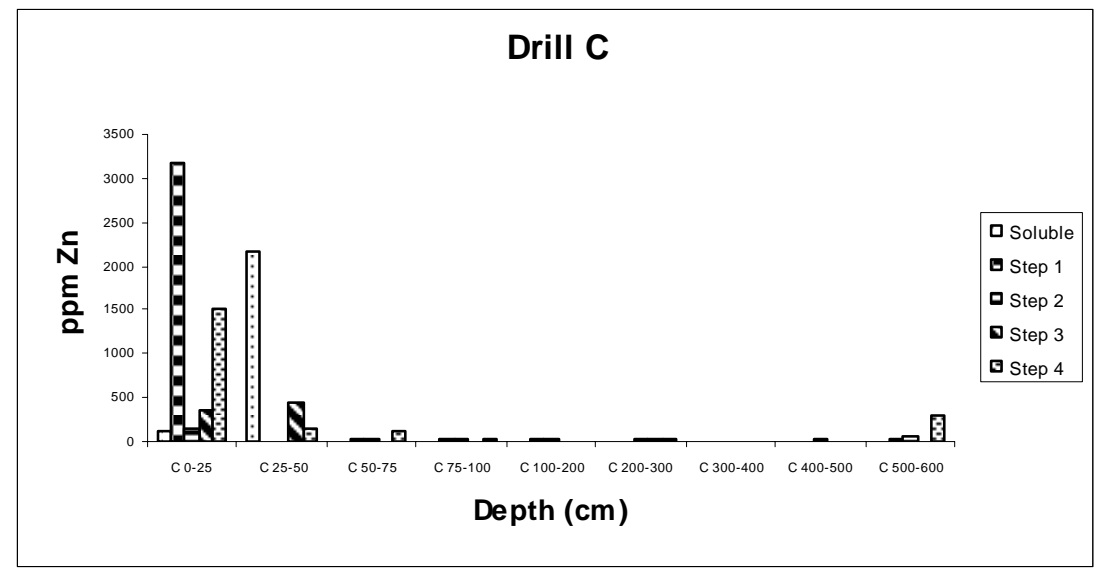

Figure 4. Metal concentration for each depth of drill C

\section{CONCLUSIONS}

Surface soils of the three drills could be considered as Spolic Anthropic Regosols enriched in sulfates and iron oxides. Regarding $\mathrm{pH}$, only some surface layers of a drill close to the sea showed a strong acid reaction at $\mathrm{pH} 4.45$ and 5.39, which mean that metals there will have a higher mobility. The particle density of the studied soils agree with generic density values for mineral soils, except for surface layers that showed higher density values, probably because of their mineralogy and the enrichness in heavy metals coming from the mining wastes.

The behaviour of zinc in function of depth was different for each drill. Drill $B$, which is placed in the middle stretch of the seasonal river, shows the highest $\mathrm{Zn}$ concentration values, with some concentrations that reach more than $40.000 \mathrm{ppm}$ of this metal. On the other hand, for the other drills there were not values higher than $4000 \mathrm{ppm}$ in both cases. For upper and lower drills, the highest zinc concentration can be found in the first meter from the soil surface, what agree with the higher particle density of these layers. Any case, for the middle drill zinc concentration increases with depth, with a major accumulation between 2-4 m. Soluble fractions are low for most of the samples, what agree with high $\mathrm{pH}$ values. Data from these analyses showed that a change of the environment conditions could remobilise great amounts of $\mathrm{Zn}$. In this sense, a change of acidic conditions could affect mainly to the lower drill. Meanwhile a change of reducing or oxidizing conditions can affect to middle and upper drills zinc remobilization.

Therefore, middle stretch of the seasonal river shows a very different behaviour in relation to zinc mobility, leachibility and distribution in soil profiles. For this river stretch, metal accumulation in the soil profile is higher, with total concentrations up to ten times higher than in the other stretches of the seasonal river, and with higher accumulation in deeper layers, what means that leachibility in this stretch can be bigger. Therefore, leachibility risks and hazards for groundwater should be higher in the middle stretch of this seasonal river. This zone is plenty of surface aquifers, what implies a major pollution risk of groundwater just in the middle part of the river run.

Besides, for drill C, Zinc mainly accumulated in soil surface $(0-5 \mathrm{~cm})$ and sharply decreased with increasing soil depth, and the concentration of $\mathrm{Zn}$ in 1-5 m depth of drill was similar with that of uncontaminated soil, which indicated $\mathrm{Zn}$ was almost not migrated and has less potential to pollute groundwater. In order to explain this situation, it must be taken into account that for this drill, only the first $85 \mathrm{~cm}$ should be considered as soil. From this point downwards all the materials should be considered as marine sediments, with a bioclastic origin and continuously under swell influence. Therefore, these deeper sediments were placed under sea hydrodynamic influence, instead of under river influence, what lead to no propitious conditions for metal precipitation. Mar Menor lagoon is a basin that is suffering a 
regression process. Thus, a great part of the sea sediments are actually covered by continental sediments, mostly with a mining origin.

On the other hand, the lower stretch of the seasonal river show a special metal distribution because of the underlying materials are placed in the saturated zone (marine aquifer); therefore, there is not a vertical flux of leaching, but a horizontal flux could be happening. Therefore, it could be considered that for this final part of the river, pollution is mainly following a horizontal direction. For middle and higher stretch leaching seems to be the mainly factor with influence on pollution, that can more frequently affect to deeper layers.

\section{ACKNOWLEDGMENTS}

This study has been performed in the framework of a project of the Spanish National Research Programme (ref. CGL2004-05963-C04-04), entitled "Integrated study of water quality in mining abandoned areas. Assessment on the surface and groundwater impacts and possible attenuation measures".

\section{REFERENCES}

Brady N.C. (2002) The nature and properties of soils, Prentice-Hall PTR, 2002. 13th Edition. Upper Saddle River, New Jersey, 960 p.

Davies B.E. (1994) Trace elements in the human environment: problems and risks, Environmental and Geochemical Health, 16, 97-106.

Doemel W.N. and Brock T.D. (1971) pH of very acid soils, NATURE, 229 (5286), 574

Emmerich W.E., Lund L.J., Page A.L., Chang A.C. (1982) Solid phase forms of heavy metals in sewage-sludge treated soils, Journal of Environmental Quality, 11, 178-181.

Evangelou V.P., Karathanasis A.D. (1991) Influence of pH, sodium adsorption ratio, and salt concentration on settling kinetics of suspended solids in coalmine ponds, Journal of Environmental Quality, 20, 783-788.

Ewers V., (1991) Standards, guidelines and legislative regulations concerning metals and their compounds, In: Merian, E. (ed.), Metals and their compounds in the environment: occurrence, analysis and biological relevance, Weinheim: $\mathrm{UCH}$.

FAO-ISRIC-ISSS (1998) World Reference base for soil Resources, Food and Agriculture Organization of the United Nations, Rome, $91 \mathrm{p}$.

Gorder G.W., Dahm P.A. (1981) Analysis of carbofuran and atrazine in soil samples, Journal of Agricultural and Food Chemistry, 29, 629- 634.

Guo M., Chorover J. (2003) Transport and fractionation of dissolved organic matter in soil columns, Soil Science, 168(2), 108-118.

Kabata-Pendias A. and Pendias H. (1992) Trace elements in soils and plants, CRC Press Inc. Boca Raton, Florida, $315 \mathrm{p}$.

Luo Y.M. and Christie P. (1998) Bioavailability of copper and zinc in soils treated with alkaline stabilized sewage sludges, Journal of Environmental Quality, 27, 335-342.

McBride M.B. (1994) Environmental Chemistry of Soils, Oxford University Press, New York, pp. 31-62.

Melis P., Dixit D., Prevoli A., Gessa C. (1983) Describing the adsorption potential determining ions on variable charge mineral surfaces, Annali, 30,137- 48.

Métodos Oficiales de Análisis (1994) Tomo III, Madrid, p. 223-225, and 239-240.

Poirria M.A., Bordelon B.R., Laseter J.L. (1972) Adsorption and concentration of dissolved carbon14 DDT by coloring colloids in surface waters, Environmental Science and Technology, $\mathbf{6}$, 1033-1035.

Sahuquillo A., Lopez-Sanchez J.F., Rubio R., Rauret G., Thomas R.P., Davidson C.M. and Ure A.M. (1999) Use of a certified reference material for extractable trace metals to assess sources of uncertainty in the BCR three-stage sequential extraction procedure, Analytica Chimica Acta, 382, $317-327$.

Sauerbeck D.R. (1991) Plant, element and soil properties governing uptake and availabilities of heavy metals derived from sewage sludge, Proceedings of an International Conference Orlando, Florida. Water, Air and Soil Pollution, 52-58, 222- 232.

Selim H.M., Zhu H. (2002) Retention and mobility of deltamethrin in soils 2: transport 1, Soil Science, 167(9), 580-589. 
Seta A.K., Karathanasis A.D. (1997) Water dispersible colloids and factors influencing their dispersibility from soil aggregates, Geoderma, 74, 255-266.

Soil Quality (1995) Extraction of trace elements soluble in aqua regia (International Standard ISO 11466: (E)).

REAL DECRETO 1310/1990, de 29 de octubre, por el que se regula la utilización de los lodos de depuración en el sector agrario. pp. 32339-32340

Robles-Arenas V.M., Rodríguez R., García C., Manteca J.I., Candela L. (2006) Sulphide mining impacts in the physical environment: Sierra de Cartagena-La Unión (SE Spain) case study, Environmental Geology, 51, 47- 64.

Tessens E. (1984) Clay migration in upland soil in Malaysia, Journal of Soil Science, 35, 615624.

Tessier A., Campbell P.G.C. and Bisson M. (1979) Sequential extraction procedure for speciation of particulate trace metals, Analytical Chemistry, 51, 844- 851.

Van Olphen H. (1977) An introduction to clay colloid chemistry, 2nd ed., New Cork (NY) Wiley and Sons.

Yukselen M.A. (2002) Characterization of heavy metals contaminated soils in Northern Cyprus, Environmental Geology, 42, 597-603.

Zhang M., Zitong G., Karathanasis A.D. (2000) Effect of perched water tables on aluminosilicate stability and soil genesis, Pedosphere, 10(3), 247- 256. 